\title{
The response mechanism of the HVA1 gene in hulless barley under drought stress
}

\author{
Xiaohua Yao, ${ }^{1-3}$ Kunlun Wu, ${ }^{1-3}$ Youhua Yao, ${ }^{1-3}$ Jie Li,,${ }^{1,2}$ Youcheng Ren, ${ }^{1-3}$ Dezhao Chi ${ }^{1-3}$ \\ ${ }^{1}$ State Key Laboratory of Plateau Ecology and Agriculture, Qinghai University, Xining; ${ }^{2}$ Qinghai Academy \\ of Agricultural and Forestry Sciences, Xining; ${ }^{3}$ Qinghai Key Laboratory of Hulless Barley Genetics and \\ Breeding, Xining, China
}

\begin{abstract}
HVA1, a member of LEA3 (late embryogenesis abundant protein, group 3 ), is closely related to water stress. However, the response of HVA1 to drought remains unknown in hulless barley. In this study, cultivars with high (Handizi), intermediate (Kunlun 12), and low (Dama) drought tolerance were selected from 28 hulless barley cultivars from the Tibet-Qinghai plateau to explore the drought response mechanism of HVA1. Then, HVA1 was cloned and the expression of the three cultivars was studied using exposure to polyethylene glycol (PEG) 6000. HVAls in the three hulless barleys were highly homologous at the nucleotide and amino acid levels with over $99 \%$ identity. Real-time quantitative polymerase chain reaction showed that the expression level of HVA1 induced by PEG 6000 had a single peak curve in the three cultivars, but higher HVAl transcript accumulation was seen in Handizi than in Kunlun 12 and Dama under the same drought stress. This result was also proved in eight hulless barleys. The expression level was a better predictor of drought resistance than the genetic structure of $H V A 1$.
\end{abstract}

\section{Introduction}

Hulless barley (Hordeum vulgare L. var. nudum Hook. f.) is a selfing annual species, with naked grains when ripening. It is widely grown on the Qinghai-Tibet plateau (suffering serious drought stress) and has been a staple food for the Tibetan people since the fifth century CE (Liang et al., 2012). Drought is an

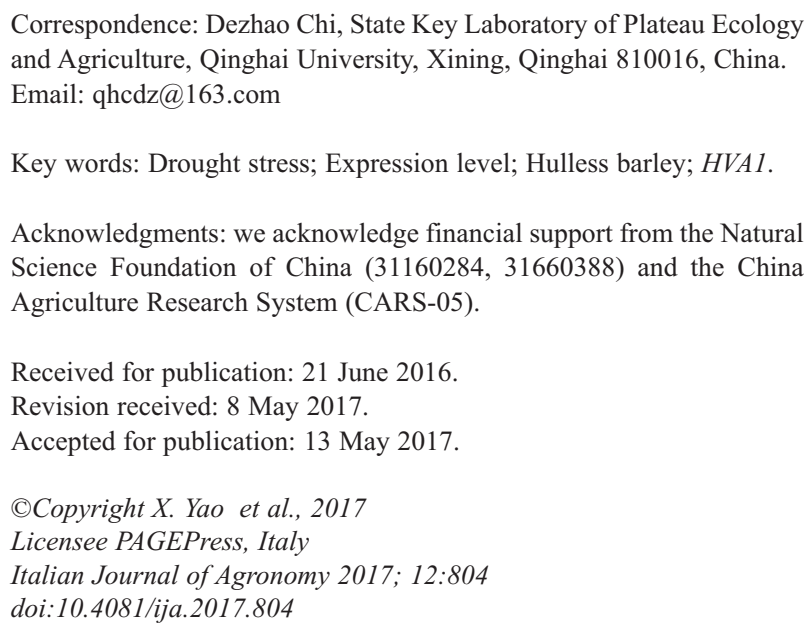

important environmental constraint that limits the productivity of barley and other crops worldwide (Romanek et al., 2011). The growth and development of plants are restrained under the stress of drought with decreases in net photosynthetic rate, respiration, leaf osmoregulation ability, and cell membrane stability (Li et al., 2016). The most susceptible stages to drought are germination, early seedling growth, and grain filling. If plants can survive drought stress during these sensitive periods, the ability of the plant to survive additional drought exposure will increase (Liang et al., 2016).

Plants have developed many physiological and biochemical reactions in response to adverse environmental conditions. Some compatible low-molecular-weight metabolites will be accumulated to protect cells against dehydration, and the most common of these is late embryogenesis abundant protein (LEA) (Park et al., 2003). LEA proteins are closely related to desiccation induced and regulated by abscisic acid (ABA) or dehydration signaling (Ramanjulu and Bartels, 2002). LEA proteins are involved in protection mechanisms against environmental stressors in plants (Liang et al., 2013). According to the homology of the amino acid sequence and presence of special primitive sequences, LEA proteins are categorised into six groups (Wise, 2003). The Hordeum vulgare aleurone1 (HVA1) gene, which belongs to group 3 LEA, is activated during cell dehydration caused by water deficit, salt stress, low temperature, or ABA induction (Romanek et al., 2011; Battaglia et al., 2008).

Most researches on the HVA1 have focused on transformation. The HVA1 plays a protective role against water tolerance in rice (Babu et al., 2004), wheat (Chauhan and Khurana, 2011), oats (Oraby et al., 2005), tobacco (Li et al., 2007) and mulberry (Checker et al., 2012). HVAl resists water stress by increasing the dry weight of plant, the fresh weight of the roots, and the dry weight of the shoots in transgenic wheat (Sivamani et al., 2000). Crops transformed by the introduction of the barley HVA1 had a significant increase in vegetative biomass and other traits associated with drought tolerance. However, the expression pattern and the mechanism of HVA1 under drought stress in hulless barley remain unknown.

\section{Materials and methods}

\section{Plant materials and growth conditions}

The 28 hulless barley cultivars were selected from 300 cultivars, which collected from several major planting provinces including Qinghai, Tibet, and Sichuan. Selection was based on high yield and disease-resistance (Table 1). The cultivars were divided into three groups based on geographic origin: Qinghai- 
Tibet Plateau (19 cultivars), Hunan and Jiangsu provinces of China ( 5 cultivars), and Mexico ( 4 cultivars). The cultivars were archived by the Qinghai Academy of Agricultural Forestry Sciences. Seeds were grown in $100 \mathrm{~mm}$ petri dishes with three layers of filter paper saturated with $10 \mathrm{~mL}$ of distilled water for $7 \mathrm{~d}$ with sufficient additional water added to maintain saturation. Seedlings were transplanted into a $100 \mathrm{~mL}$ breaker (10 plants per breaker) with $20 \mathrm{~mL}$ distilled water. The seedlings were maintained in an incubator at $25^{\circ} \mathrm{C}$ with $2000 \mathrm{~lx}$ lighting intensity and a $14 \mathrm{~h}: 10 \mathrm{~h}$ light:dark photoperiod.

\section{Detection of relative water content and relative water loss rate}

When the third leaves of 28 hulless barley varieties were fully expanded (15 d after sowing), they were removed to measure the relative water content and dehydration rate according to a previously described protocol (Chapotin et al., 2003). We used the following formula: Relative water content $(\mathrm{RWC})(\%)=[($ Fresh quality-Dry quality)/(Saturated quality-Dry quality)] $\times 100 \%$; Relative water loss rate $(\mathrm{RWL})\left(\mathrm{g} \cdot \mathrm{g}^{-1} \mathrm{DW} \cdot \mathrm{h}^{-1}\right)=($ Fresh qualityquality after $24 \mathrm{~h}$ dehydration $) /($ Dry quality $\times 24)$.

\section{Polyethylene glycol 6000 treatment}

Based on the RWC and RWL results, Handizi, Kunlun 12, and Dama were selected for further experiments. These three cultivars were treated with different concentrations $(0,5,10,15,20,25$, and $30 \%$ ) of polyethylene glycol (PEG) 6000 (Sigma Aldrich, Saint Louis, MO, USA) at the three-leaf stage in an incubator at $25^{\circ} \mathrm{C}$ with 2000 lx lighting intensity and a 14h:10h light:dark photoperiod. Sufficient PEG 6000 solution was added to each dish every day so that simulated drought conditions could be maintained for $3 \mathrm{~d}$. Then the relative conductivity and malondialdehyde content of leaves were measured according to Karami et al. (2013), while the soluble protein content of leaves was determined according to Bradford (1976).

\section{Isolation of the $\mathrm{HVAI}$}

Total RNA was extracted from the leaf tissues of Handizi, Kunlun 12 and Dama using MiniBEST Plant RNA Extraction Kit (TaKaRa, Kusatsu, Japan). The integrity of RNA was determined by electrophoresis on a $1.0 \%$ formaldehyde-denatured agarose gel stained with Gold View. The quality and quantity of RNA was determined by measuring the $\mathrm{OD}_{260 / 280}$ and $\mathrm{OD}_{260}$ with a SmartSpec Plus spectrophotometer (Bio-Rad, Hercules, CA, USA). The cDNA was synthesised using Superscript First-Strand Synthesis System for RT-PCR (TaKaRa) and an adaptor-oligo (dT) primer following manufacturer instructions. Primers were designed and used to amplify the cDNA of the HVAlgene (Table 2). Primers (P1) were designed to amplicate HVAl according to the sequence in GenBank (ID: X78205.1). The PCR amplification conditions were $94^{\circ} \mathrm{C}$ for $5 \mathrm{~min}$ followed by 30 cycles at $94^{\circ} \mathrm{C}$ for $1 \mathrm{~min} ; 64^{\circ} \mathrm{C}$ for $40 \mathrm{~s} ; 72^{\circ} \mathrm{C}$ for $1 \mathrm{~min}$ and a final $72^{\circ} \mathrm{C}$ for $8 \mathrm{~min}$. The PCR products were cloned into the pMD20-T vector (TaKaRa), and then transformed into E. coli DH5a. Five positive clones were sent for sequencing.

\section{Semi-quantitative polymerase chain reaction and quan- titative real-time polymerase chain reaction}

Total RNA was extracted from the leaves of Handizi, Kunlun 12 and Dama which were soaked in 0 to $30 \%$ PEG 6000 for $3 \mathrm{~d}$. The total RNA was then reverse transcribed into cDNA as a template for PCR. The semi-quantitative PCR primers of HVA1 were P1. Primers (P2) of reference gene $\beta$-actin were designed according to barley actin (ID: AY145541). The cycling parameters of semiquantitative PCR amplification were: $95^{\circ} \mathrm{C}$ for $5 \mathrm{~min}$ followed by 32 cycles at $94^{\circ} \mathrm{C}$ for $60 \mathrm{~s}, 64^{\circ} \mathrm{C}$ for $60 \mathrm{~s}, 72^{\circ} \mathrm{C}$ for $90 \mathrm{~s}$ and a final $72^{\circ} \mathrm{C}$ for $10 \mathrm{~min}$. The quantitative real-time PCR primers (P3) were designed according to the HVA1 and the primers (P4) of the reference gene were designed from $18 \mathrm{~S}$ rRNA. The qPCR amplification conditions were $95^{\circ} \mathrm{C}$ for $3 \mathrm{~min}$ followed by 40 cycles at $95^{\circ} \mathrm{C}$ for $10 \mathrm{~s}, 61^{\circ} \mathrm{C}$ for $30 \mathrm{~s}$, then $95^{\circ} \mathrm{C}$ for $1 \mathrm{~min}, 61^{\circ} \mathrm{C}$ for $1 \mathrm{~min}$ and a final 40 cycles at $61^{\circ} \mathrm{C}$ for $10 \mathrm{~s}$. The fluorescence signals obtained were measured once for each cycle at the extension step. All the reactions were performed in a DNA Engine Opticon ${ }^{\mathrm{TM}} 2$ system (Bio-Rad) following manufacturer recommendations.

\section{Data analysis}

All physiological and gene expression measurements were replicated at least three times with independent plant samples and the mean was used for result analysis and discussion. Means, standard deviation (SD) and statistical analysis were performed using SPSS package (version 18.0). All data were subjected to variance analy-

Table 1. Names and sources of the hulless barley cultivars used in this study.

\begin{tabular}{|c|c|c|c|c|c|}
\hline Number & Name & Source & Number & Name & Source \\
\hline 1 & Dama & Gansu & 15 & GolasCley & Mexico \\
\hline 2 & Ganziheiliuleng & Sichuan & 16 & Xiang 84-26-174 & Hunan \\
\hline 3 & Sunong 401 & Jiangsu & 17 & Zangqing 80 & Xizang \\
\hline 4 & Xiang 1146 & Hunan & 18 & Sunjiazhuangbai & Gansu \\
\hline 5 & Crime & Mexico & 19 & Minxian & Sichuan \\
\hline 6 & 9748 & Gansu & 20 & Dulihuang & Gansu \\
\hline 7 & Daimao & Sichuan & 21 & Changshengzi & Gansu \\
\hline 8 & Aba 330 & Sichuan & 22 & Dagestam & Mexico \\
\hline 9 & Kunlun 10 & Xining & 23 & Rudong 4 & Jiangsu \\
\hline 10 & Beiqing 1 & Qinghai & 24 & Beiqing 3 & Qinghai \\
\hline 11 & Lasagoumang & Xizang & 25 & Gaoyuanzao 1 & Qinghai \\
\hline 12 & Kunlun 12 & Xining & 26 & Horl726 & Mexico \\
\hline 13 & Kangqing 7 & Sichuan & 27 & Liulengtou & Gansu \\
\hline 14 & Xiang 0888 & Hunan & 28 & Handizi & Sichuan \\
\hline
\end{tabular}


sis (ANOVA) and the mean differences were compared by the least significant difference (LSD) test. Nucleotides and amino acid sequence analyses were performed with the DNAMAN program version 5. 2. 2 (Lynnon Corp., San Ramon, CA, USA). 2- $\triangle \Delta C T$ methods were used in quantifying the relative changes of gene expression (Pfaffl, 2001).

\section{Results}

\section{Identification of drought resistance in hulless barley cultivars}

The RWC and RWL results of the 28 cultivars showed that the relative water content was the highest $(60.16 \%)$ and the relative water loss rate was the lowest $(8.80 \%)$ in Handizi, and the relative water content was the lowest (38.98\%) and the dehydration rate was the highest $(20.20 \%)$ in Dama (Figure 1A). These two parameters in Kunlun 12 were intermediate. The results suggested that Dama was the most sensitive to water loss stress and Handizi was the least sensitive, with Kunlun 12 being intermediate. Dama, Kunlun 12 and Handizi were selected for the next experiments.

We detected the RWC and ABA content of Kunlun 12 with PEG 6000 treatment. With increasing PEG 6000 concentration, the leaf RWC of Kunlun 12 gradually decreased (Figure 1B) and ABA content initially increased and then decreased (Figure 1C). The relationship between RWC and PEG 6000 concentration was linear, while the ABA content and PEG 6000 concentration relationship was a non-linear quadratic function. Therefore, it is possible to use PEG 6000 as an osmotic agent to simulate drought and water stress. The effects of PEG 6000 on leaf soluble protein content, relative conductivity, and malondialdehyde content were determined in Handizi, Kunlun 12, and Dama cultivars. The soluble protein content of the three cultivars initially increased and then decreased with increasing PEG 6000 concentration (Figure 2A). Compared with the control group, the protein content increased significantly at 5-15\% PEG 6000 in Handizi and Kunlun 12, but decreased at $20-30 \%$ PEG 6000 in all three cultivars $(\mathrm{P}<0.01)$. However, in each group, the soluble protein content of Handizi was the highest, followed by Kunlun 12 and Dama. The results of relative conduc- tivity and the malondialdehyde content were opposite those of the soluble protein content, with Handizi being the lowest, Kunlun 12 intermediate, and Dama the highest (Figure 2B and C). These results indicated that Handizi was the best drought-resistance cultivar, followed by Kunlun 12 and Dama.

\section{Cloning and multiple sequence alignment of $\mathrm{HVAls}$ from three cultivars}

The cDNA sequences of the three HVA1s were 642 bp (Figure 3). Each of the cDNA sequences encoded 213 amino acids. Sequence comparison showed that the deduced amino acid sequence of HVA1-Handizi and HVA1-dama were identical, and HVA1Kunlun12 was identical with them except for residue 197. Nine imperfect repeats of the 11 amino acids (Thr-Glu-Ala-Ala-LysGln-Lys-Ala-Ala-Glu-Thr) were found in the three polypeptides.

\section{Expression of the HVA1 in hulless barley using semi- quantitative and quantitative polymerase chain reac- tions}

The expression level of $H V A 1$ in the three varieties was very low in distilled water and 5\% PEG 6000. However, the expression was considerably greater in 10 30\% PEG 6000 (Figure 4A). The expression of the HVAl was detected by qPCR. The results showed that the expression of HVA1 was not significantly different in the control and 5\% PEG 6000 groups, which is consistent with the semi-quantitative PCR results. The expression of HVA1 increased

Table 2. Sequences of primers used in this study.

\begin{tabular}{ll} 
Name & Sequence \\
P1 & F:5 - TTTGGATCCATGGCCTCCAACCAGAACC -3 \\
P2 & R: 5 - GGGGAGCTCCGAACGACCAAACACGACT -3 \\
\hline P3 & F: 5 - TCACGCTCAAGTACCCCATCGA -3 \\
P4 & R: 5 - GGAGCTGTTCTTGGCAGTCTCCA -3 \\
& F: 5 - GCAGCGTCCTCCAGCA -3 \\
& R: 5 - GGTGTTGTCCCCTCCCA -3 \\
& F: 5 - CAAGTATGTCATAGAGATTTGAA -3 \\
& R: 5 - GTAACCGAAGTCACAAATCT -3 \\
\hline
\end{tabular}

A

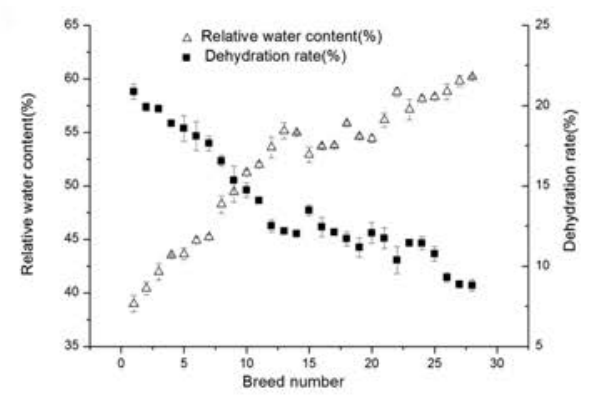

B

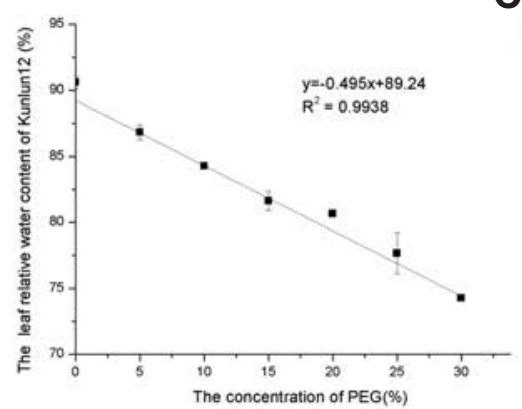

C

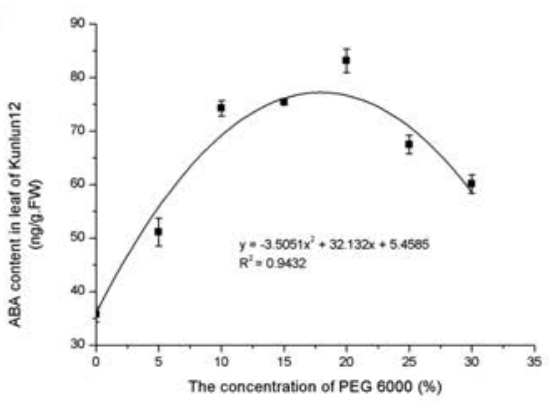

Figure 1. Resistance against water loss. A) Relative water content and dehydration rate of different varieties of hulless barley. The breed number indicates the different barley variety. B) The relationship between leaf relative water content of Kunlun 12 and polyethylene glycol (PEG) concentration. C) The relationship between leaf abscisic acid content of Kunlun 12 and PEG concentration. Error bars indicate the mean \pm standard deviation from three independent experiments. 
from $10 \%$ to $30 \%$ in the PEG 6000 group, and reached the highest level in the $20-25 \%$ PEG 6000 treatment in three cultivars. The expression level of the HVA1 in Handizi was the highest at each point, followed by Kunlun 12 and Dama, and the difference of expression level in the three cultivars was significant when treated with 10 to $30 \%$ solutions of PEG 6000 . The highest expression level occurred at 25\% PEG 6000 in Handizi and Kunlun 12, but at $20 \%$ PEG 6000 in Dama. Compared to the expression levels in 1\% PEG, the highest transcription levels of HVAl were increased by 803-, 490- and 323-fold respectively (Figure 4B). The range of HVA1 expression level in Handizi was wider than Kunlun 12 and Dama (Figure 4C). In addition, we tested the expression level of HVA1 from 8 cultivars with 25\% PEG 6000 treatment by qPCR. The expression level of HVA1 increased from breed number 1 (Dama) to number 28 (Handizi) (Figure 4D). The difference of expression levels among the 8 cultivars was significant $(\mathrm{P}<0.01)$.

\section{Discussion}

Previous research demonstrated that a low PEG concentration promoted seed germination, seedling growth and improvement in the physiological function of hulless barley, while a high PEG concentration inhibited these functions (Yao and $\mathrm{Wu}, 2012$ ). In this study we found that a low PEG concentration increased soluble protein content, but also decreased relative conductivity and malondialdehyde content. PEG 6000 is a non-ionic, water-soluble polymer, which does not rapidly penetrate intact plant tissues (Chazen et al., 1995). High MW PEG (6000-8000) is recommended for use in nutrient culture (Comeau et al., 2010; Blum, 2008). Therefore, it was reasonable to use PEG 6000 as an osmotic agent.

The functional roles and mechanisms of LEAs remain unclear. This drought-related candidate gene might be involved in plant adaptation to drought stress. It was identified through QTL analysis of Tadmor and ER/Apm Recombinant Inbreed Line (RIL) pop-
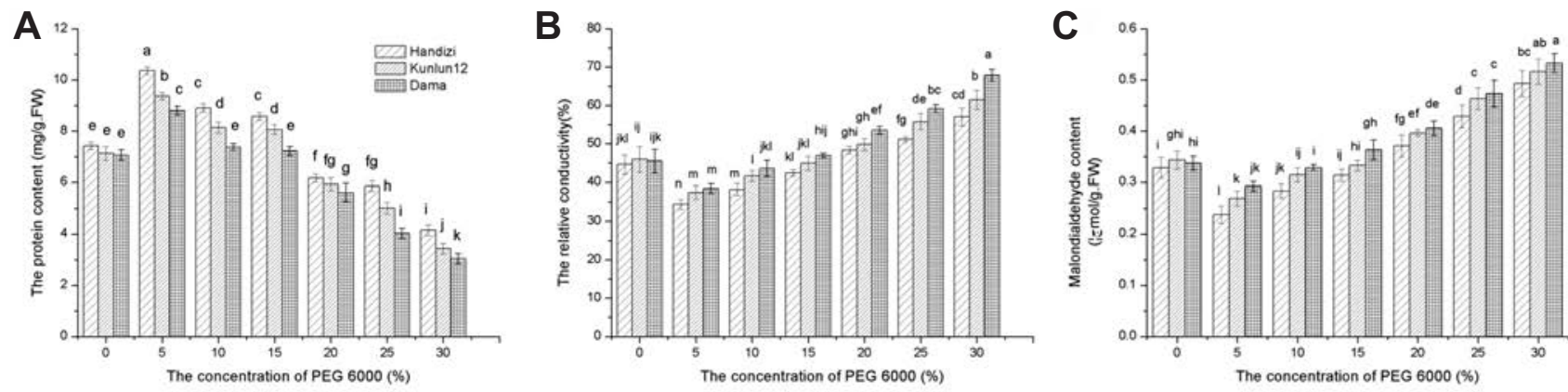

Figure 2. Drought resistance of Handizi, Kunlun12 and Dama. Effect of polyethylene glycol 6000 on leaf soluble protein content (A), relative conductivity $(B)$ and malondialdehyde content $(C)$ in Handizi, Kunlun 12 and Dama. Error bars indicate the mean \pm standard deviation from three independent experiments. Different letters indicate significant $(\mathbf{P}<0.05)$ differences between cultivars.

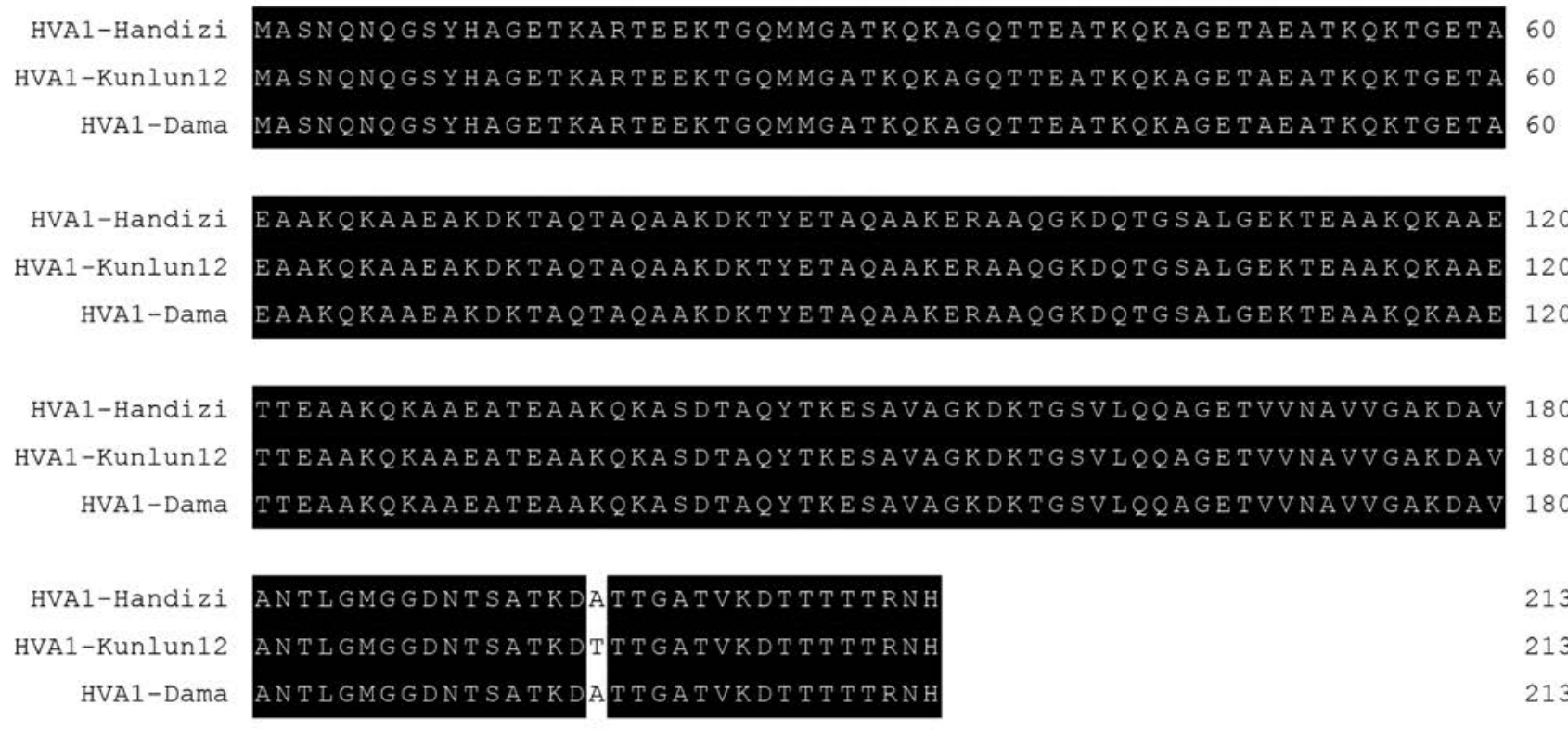

Figure 3. Multiple alignments of the HVA1 deduced amino acid sequences from Handizi, Kunlun 12 and Dama. The sequences were aligned using the ClustalW programme. 
ulations (Du et al., 2004; Cseri et al., 2011). Under both salinity and drought stress, transgenic HVAl mulberry plants showed improved cellular membrane stability (CMS), higher photosynthetic yield, less photo-oxidative damage, and better water use efficiency compared to the non-transgenic plants (Lal et al., 2008). When the HVAl was transferred into maize, the transgenic plants had increased leaf relative water content (RWC), greater leaf and root biomass, and increased survival under complete $15 \mathrm{~d}$ drought while all wild-type non-transgenic control plants died (Nguyen and Sticklen, 2013). In malting barley genotypes, $\mathrm{CO}_{2}$ assimilation rates and PSII efficiency in drought conditions were related to both water content and the accumulation of HVAl transcript in leaves (Rapacz et al., 2010). However, another group 3 LEA gene PcC306, isolated from Craterostigma plantagineum, failed to improve the drought resistance ability of transgenic tobacco (Hong et al., 1992). Accordingly, is there a link between HVAl and drought stress in hulless barley? What is the mechanism of HVA1 in drought tolerance of hulless barley? Drought tolerance in barley was highly correlated with HVA1 (Qian et al., 2007; Wójcik-Jagła et al., 2012). Our results also show this positive correlation. Variation in the drought resistance of hulless barley was caused by amino acid changes in HVA1 (Qian et al., 2007). In this study, we selected three drought resistant cultivars from among 28 hulless barley cultivars according to their relative water content and dehydration rate. Then, we cloned HVAls from the three cultivars, which were highly homologous at nucleotide and amino acid level with over $99 \%$ identities. We found that the expression level of the HVA1 in drought-resistant cultivars was higher than expression in drought-sensitive hulless barley under the same water stress. Therefore, we suggest that different HVAl expression levels caused different levels of drought resistance in the three cultivars.

LEA protein is widely distributed in cells and plays an important role in stabilising cell membranes as a molecular barrier, combining ions, and protecting cells from oxidation. These functions are necessary for plant survival under high stress levels (Baker et al., 1988). LEA protein may also be a regulatory protein involved in plant osmotic adjustment and it may protect the endosperm and growing tissue from osmotic stress (Brini et al., 2007). Therefore, the protein produced by the HVA1 is involved in osmotic regulation, possibly by protecting membranes from instability when the plant experiences water stress. The expression of the HVA1 in hulless barley initially increased with an increase in osmotic stress,
A

$\begin{array}{lllllllllllllll}1 & 2 & 3 & 4 & 5 & 6 & 7 & \text { a } & \text { b } & \text { c } & \text { d } & \text { e } & \text { f } & g & \text { M }\end{array}$
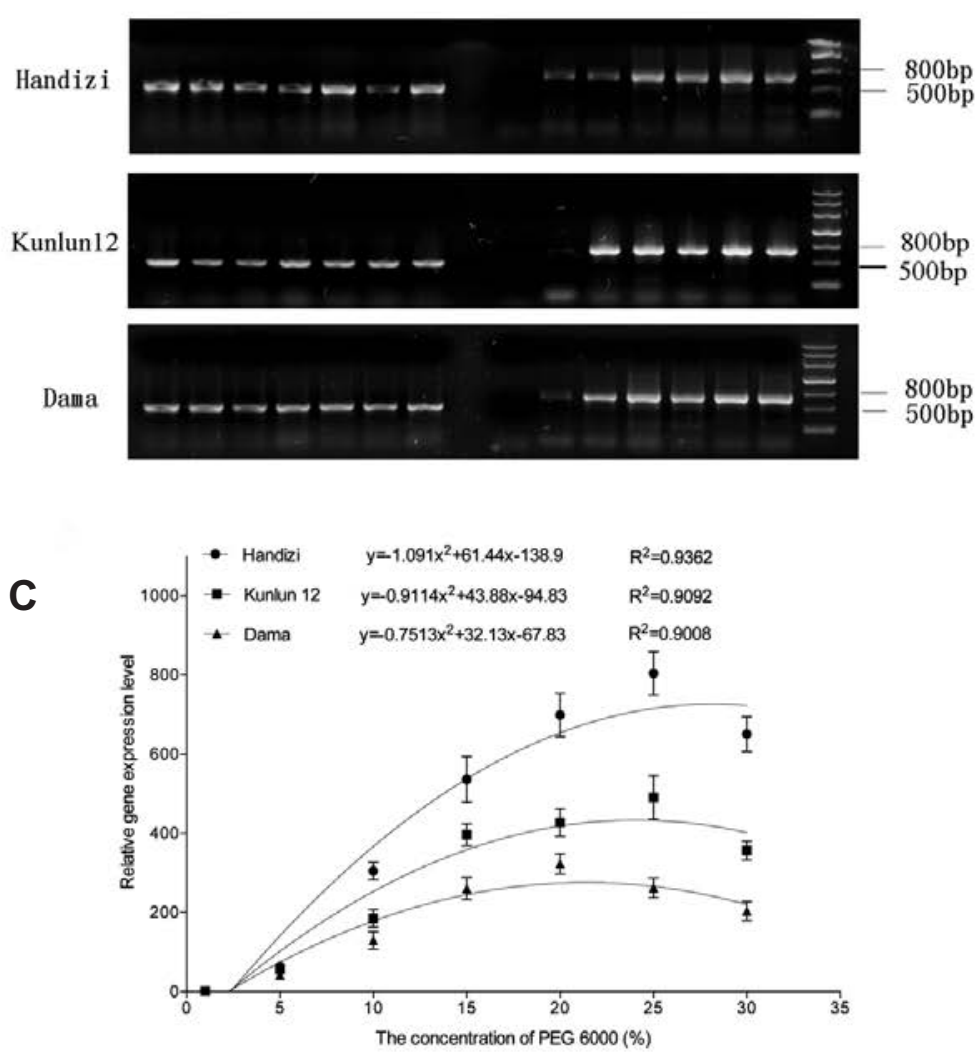

B
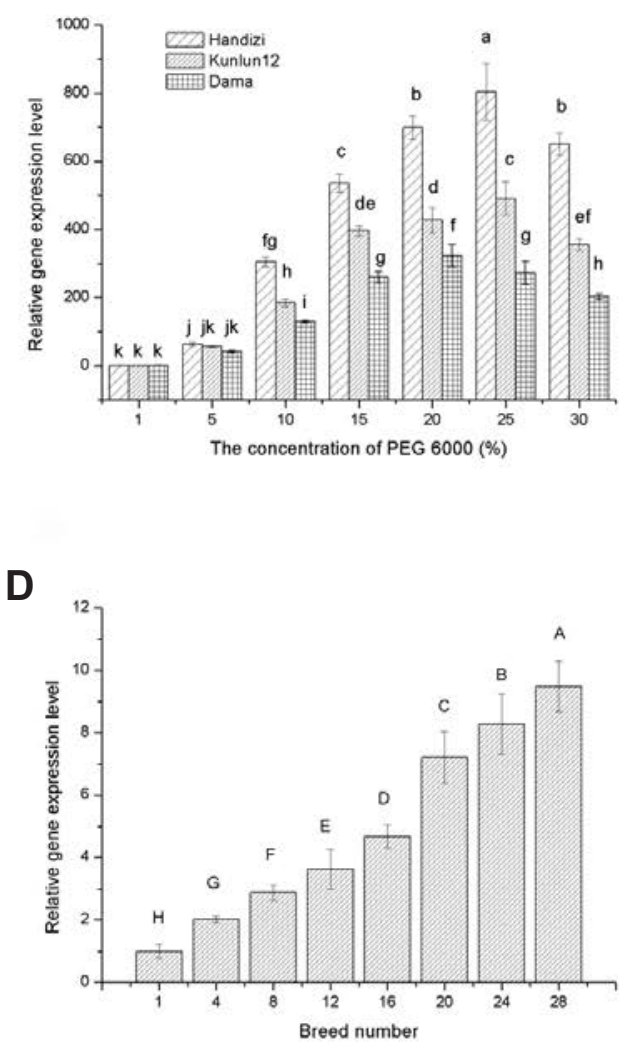

Figure 4. Expression levels of HVA1 in hulless barley. Values for quantitative polymerase chain reaction are means \pm standard deviation of five replicates. Different letters indicate significant $(\mathbf{P}<\mathbf{0 . 0 5})$ differences between treatments. A) Relative expression levels of $H V A 1$ in Handizi, Kunlun 12 and Dama tested by RT-PCR. 1-7, Expression levels of $\beta$-Actin under PEG 6000 (0, 5, 10, 15, 20, 25 and 30\%); a-g, expression levels of $H V A 1$ under PEG $6000(0,5,10,15,20,25$ and 30\%); M, marker. B) Relative expression levels of $H V A 1$ in Handizi, Kunlun 12 and Dama tested by quantitative real-time polymerase chain reaction (qRT-PCR). C) Expression profiling of $H V A 1$ under PEG 6000. D) Relative expression levels of HVA1 in eight cultivars tested by qRT-PCR. 
but decreased under prolonged stress. The reason might be that during the initial stages of the drought, plants need substantial LEA protein in order to rapidly stabilise and repair cytomembranes. Under continued water stress, the metabolic system of the plant may restrict the expression of the HVA1. This hypothesis was supported by qPCR results. Handizi had greater tolerance to PEG 6000 than Kunlun 12 and Dama. Compared to the expression levels in $1 \%$ PEG, the transcription levels of HVAl at its highest point increased by $803-$, 490- and 323-fold in Handizi, Kunlun12, and Dama, respectively. However, the highest transcription levels in Handizi and Kunlun 12 were at 25\% PEG 6000; in Dama highest transcription was at $20 \%$ PEG 6000 . Also, based on regression formula extrapolation, $H V A 1$ was no longer expressed in $53.97 \%$ PEG 6000 in Handizi, 45.88\% PEG 6000 in Kunlun 12, and 40.70\% PEG 6000 in Dama.

\section{Conclusions}

Coping with the variability of biotic and abiotic stresses is essential in sustainable agriculture. Conventional breeding approaches can be used to develop improved varieties of hulless barley but the long time required supports the additional use of more precise biotechnological approaches. Genetic engineering techniques hold great promise for developing crop cultivars with drought tolerance (Checker et al., 2012). Understanding the mechanisms behind stress tolerance in crops under realistic conditions could accelerate drought resistance improvements in hulless barley. This study offers a process for identifying favorable cultivars and genetic controls of drought resistance in hulless barley. Drought resistance of plants is a quantitative character controlled by many genes, such as OjERF (Li et al., 2012) and Dhn (Saibi et al., 2015), but the HVAl appears to be a key component. Knowledge of the expression level of the HVAl under drought stress might be useful for breeding hulless barley with enhanced drought tolerance, but the interactions between HVA1 and other drought resistance genes require further studies.

\section{References}

Babu RC, Zhang J, Blum A, Ho THD, Wu R, Nguyen H, 2004. HVA1, a LEA gene from barley confers dehydration tolerance in transgenic rice (Oryza sativa L.) via cell membrane protection. Plant. Sci. 166:855-62.

Baker J, Van dennSteele C, Dure III L, 1988. Sequence and characterization of 6 Lea proteins and their genes from cotton. Plant. Mol. Biol. 11:277-91.

Battaglia M, Olvera-Carrillo Y, Garciarrubio A, Campos F, Covarrubias AA, 2008. The enigmatic LEA proteins and other hydrophilins. Plant. Physiol. 148:6-24.

Blum A, 2008. Use of PEG to induce and control plant water deficit in experimental hydroponics culture. Available from: http://www.plantstress.com/methods/peg.htm

Bradford MM, 1976. A rapid and sensitive method for the quantitation of microgram quantities of protein utilizing the principle of protein-dye binding. Anal. Biochem. 72:248-54.

Brini F, Hanin M, Lumbreras V, Amara I, Khoudi H, Hassairi A, Pages M, Masmoudi K, 2007. Overexpression of wheat dehydrin DHN-5 enhances tolerance to salt and osmotic stress in Arabidopsis thaliana. Plant. Cell. Rep. 26:2017-26.
Chapotin S, Holbrook NM, Morse S, Gutiérrez M, 2003. Water relations of tropical dry forest flowers: pathways for water entry and the role of extracellular polysaccharides. Plant. Cell. Environ. 26:623-30.

Chauhan H, Khurana P, 2011. Use of doubled haploid technology for development of stable drought tolerant bread wheat (Triticum aestivum L.) transgenics. Plant. Biotechnol. J. 9:408-17.

Chazen O, Hartung W, Neumann P, 1995. The different effects of PEG 6000 and $\mathrm{NaCI}$ on leaf development are associated with differential inhibition of root water transport. Plant. Cell. Environ. 18:727-35.

Checker VG, Chhibbar AK, Khurana P, 2012. Stress-inducible expression of barley Hval gene in transgenic mulberry displays enhanced tolerance against drought, salinity and cold stress. Transgenic. Res. 21:939-57.

Comeau A, Nodichao L, Collin J, Baum M, Samsatly J, Hamidou D, Langevin F, Laroche A, Picard E, 2010. New approaches for the study of osmotic stress induced by polyethylene glycol (PEG) in cereal species. Cereal. Res. Commun. 38:471-81.

Cseri A, Cserháti M, Von Korff M, Nagy B, Horváth GV, Palágyi A, Pauk J, Dudits D, Törjék O, 2011. Allele mining and haplotype discovery in barley candidate genes for drought tolerance. Euphytica 181:341-56.

Du JY, Chen XY, Li W, Gao Q, 2004. Osmoregulation mechanism of drought stress and genetic engineering strategies for improving drought resistance in plants. J. For. Res. 6:56-62.

Hong B, Barg R, Ho T-HD, 1992. Developmental and organ-specific expression of an ABA-and stress-induced protein in barley. Plant. Mol. Biol. 18:663-74.

Karami A, Shahbazi M, Niknam V, Shobbar ZS, Tafreshi RS, Abedini R, Mabood HE, 2013. Expression analysis of dehydrin multigene family across tolerant and susceptible barley (Hordeum vulgare L.) genotypes in response to terminal drought stress. Acta Physiol. Plant. 35:2289-97.

Lal S, Gulyani V, Khurana P, 2008. Overexpression of HVA1 gene from barley generates tolerance to salinity and water stress in transgenic mulberry (Morus indica). Transgenic. Res. 17:651-63.

Li C, Han LB, Zhang X, 2012. Enhanced drought tolerance of tobacco overexpressing OJERF gene is associated with alteration in proline and antioxidant metabolism. J. Amer. Soc. Hort. Sci. 137:107-13.

Li N, Zhao Q, Huang J, Zhao YJ, Zhang SH, 2007. Research on the transformation and expression of HVA1 gene from sixrow barley in tobacco. Biotechnol. Bull. 4:139-44.

Li Y, Chen W, Chen J, Shi H, 2016. Vulnerability to droughtinduced cavitation in shoots of two typical shrubs in the southern Mu Us Sandy Land, China. J. Arid Land. 8:125-37.

Liang J, Zhou M, Zhou X, Jin Y, Xu M, Lin J, 2013. JcLEA, a novel LEA-like protein from Jatropha curcas, confers a high level of tolerance to dehydration and salinity in Arabidopsis thaliana. PLoS One 8:e83056.

Liang JJ, Deng GD, Long H, Pan ZF, Wang CP, Cai P, Xu DL, Nima ZX, Yu MQ, 2012. Virus-induced silencing of genes encoding LEA protein in Tibetan hulless barley (Hordeum vulgare ssp. vulgare) and their relationship to drought tolerance. Mol. Breed. 30:441-51.

Nguyen TX, Sticklen M, 2013. Barley HVA1 gene confers drought and salt tolerance in transgenic maize (Zea mays L.). Adv. Crop. Sci. Tech. 1:2.

Oraby HF, Ransom CB, Kravchenko AN, Sticklen MB, 2005. Barley gene confers salt tolerance in R3 transgenic oat. Crop. Sci. 45:2218-27.

Park SH, Jun SS, An G, Hong YN, Park MC, 2003. A comparative 
study on the protective role of trehalose and LEA proteins against abiotic stresses in transgenic Chinese cabbage (Brassica campestris) overexpressing CaLEA orotsA. J. Plant. Biol. 46:277-86.

Pfaffl MW, 2001. A new mathematical model for relative quantification in real-time RT-PCR. Nucl. Acid. Res. 29:e45.

Qian G, Han ZX, Zhao T, Deng GB, Pan ZF, Yu MQ, 2007. Genotypic variability in sequence and expression of HVA1 gene in Tibetan hulless barley, Hordeum vulgare ssp. vulgare, associated with resistance to water deficit. Crop Pasture Sci. 58:425-31.

Ramanjulu S, Bartels D, 2002. Drought-and desiccation-induced modulation of gene expression in plants. Plant Cell Environ. 25:141-51.

Rapacz M, Kościelniak J, Jurczyk B, Adamska A, Wójcik M, 2010. Different patterns of physiological and molecular response to drought in seedlings of malt-and feed-type barleys (Hordeum vulgare). J. Argon. Crop Sci. 196:9-19.

Romanek J, Walczak H, Wójcik-Jagła M, Jurczyk B, Rapacz M, 2011. The effect of simulated drought on HVA1 and SRG6 gene expression in spring barley. Biotechnology 14:4.

Saibi W, Drira M, Yacoubi I, Feki K, Brini F, 2015. Empiric, structural and in silico findings give birth to plausible explanations for the multifunctionality of the wheat dehydrin (DHN-5). Acta Physiol. Plant. 37:1-8.

Sivamani E, Bahieldin A, Wraith JM, Al-Niemi T, Dyer WE, Ho T$\mathrm{HD}, \mathrm{Qu} \mathrm{R}, 2000$. Improved biomass productivity and water use efficiency under water deficit conditions in transgenic wheat constitutively expressing the barley HVA1 gene. Plant Sci. 155:1-9.

Wise MJ, 2003. LEAping to conclusions: a computational reanalysis of late embryogenesis abundant proteins and their possible roles. BMC Bioinform. 4:52.

Wójcik-Jagła M, Rapacz M, Barcik W, Janowiak F, 2012. Differential regulation of barley (Hordeum distichon) HVA1 and SRG6 transcript accumulation during the induction of soil and leaf water deficit. Acta Physiol. Plant. 34:2069-78.

Yao XH, Wu KL, 2012. Effect of PEG pretreatment on germination and growth physiology of hulless barley. Acta Bot. Boreali-Occidential. Sin. 7:1403-11. 